\title{
Unique Outbreak of Rift Valley Fever in Sudan, 2019
}

\author{
Ayman Ahmed, Yousif Ali, Adel Elduma, Mawahib Hassan Eldigail, Rehab Abdallah Mhmoud, \\ Nouh Saad Mohamed, Thomas G. Ksiazek, Isabelle Dietrich, Scott C. Weaver
}

We report a unique outbreak of Rift Valley fever in the Eldamar area, Sudan, May-July 2019, that resulted in 1,129 case-patients and $19(1.7 \%)$ deaths. Patients exhibited clinical signs including fever $(100 \%)$, headache $(79 \%)$, and bleeding (4\%). Most (98\%) patients also reported death and abortions among their livestock.

$\mathrm{R}$ ift Valley fever (RVF) is an arboviral disease Coused by RVF virus (RVFV; genus Phlebovirus, family Phenuiviridae) (1). RVFV periodically emerges to cause epizootics among livestock and epidemics in persons living nearby (2). It is mainly transmitted by the bite of infected mosquitoes or by direct contact with infected animals and their products (3). In addition, RVFV transmission is maintained vertically among both humans and vector mosquito populations $(4,5)$.

The public health threat from arboviral diseases is growing rapidly in Sudan $(4,6)$. Increasing human movement, often arising from armed conflict, is driving several arboviral diseases to emerge in Sudan, usually in the form of undifferentiated febrile illness. Recent epidemics include dengue fever $(6,7)$, Crimean-Congo hemorrhagic fever, West Nile virus disease (8), yellow fever, and chikungunya fever (4). RVF outbreaks represent major public health and economic burdens on endemic countries, particularly those such as Sudan that rely on exporting animals and animal products $(3,4,9)$. In a recent study, RVFV infection was also associated with spontaneous abor-

Author affiliations: University of Khartoum, Khartoum, Sudan (A. Ahmed); University of Texas Medical Branch, Galveston, Texas, USA (A. Ahmed, T.G. Ksiazek, S.C. Weaver); World Reference Center for Emerging Viruses and Arboviruses, Galveston (A. Ahmed, S.C. Weaver); Sudan Federal Ministry of Health, Khartoum (Y. Ali, A. Elduma, M.H. Eldigail); River Nile State Ministry of Health, Eldamar, Sudan (R.A. Mhmoud); Nile University, Khartoum (N.S. Mohamed); The Pirbright Institute, Pirbright, UK (I. Dietrich)

DOI: https://doi.org/10.3201/eid2612.201599 tion among pregnant women in Sudan (10). We describe a unique, undeclared outbreak of RVF in River Nile state, in northern Sudan, leading to the potential spread of the virus to other states in Sudan or neighboring countries.

\section{The Study}

Rift Valley fever cases initially appeared on May 23, 2019, in Eldamar, the capital city of River Nile state (Figure 1). This region, characterized as a desert environment, is in general rural and peri-urban; most of the population relies on farming, animal breeding, and more recently, traditional gold mining. By July 18 , a total of 1,129 cases had been identified on the basis of clinical signs and symptoms. The outbreak peaked in June 2019 with $\approx 96$ cases reported daily (Figure 2).

Most RVF cases, 1,120 (99.2\%), were from Eldamar, with only 7 cases reported in Barbar and 2 in Atbara (Table). The male:female ratio was 1.2:1. Adults 25-44 years of age were most affected (34.6\%), but other age groups were similarly represented; however, only $6.1 \%$ of cases involved children $<5$ years old (Table). Many of the patients (34\%) worked in farming and animal product production.

Among the 1,129 patients, $100 \%$ had fever, $79 \%$ $(892 / 1,129)$ had headache, and only $4 \%(45 / 1,129)$ had clinically manifested bleeding. Almost all (98\%; $1,104 / 1,129)$ patients (or their guardians, in the case of children) reported death or abortion among their domestic livestock. Of the 19 reported human deaths, $6(32 \%)$ were children $<15$ years of age and $9(47.4 \%)$ were farmers (Table 1 ).

We retrospectively analyzed data collected by active surveillance during this epidemic to confirm that RVFV was the exclusive causative agent of this outbreak, because it is normally associated with the rainy season in Sudan. Surveillance was established by the River Nile State Ministry of Health. In our analysis, we included variables such as patient age and sex; signs and symptoms, such as fever, 


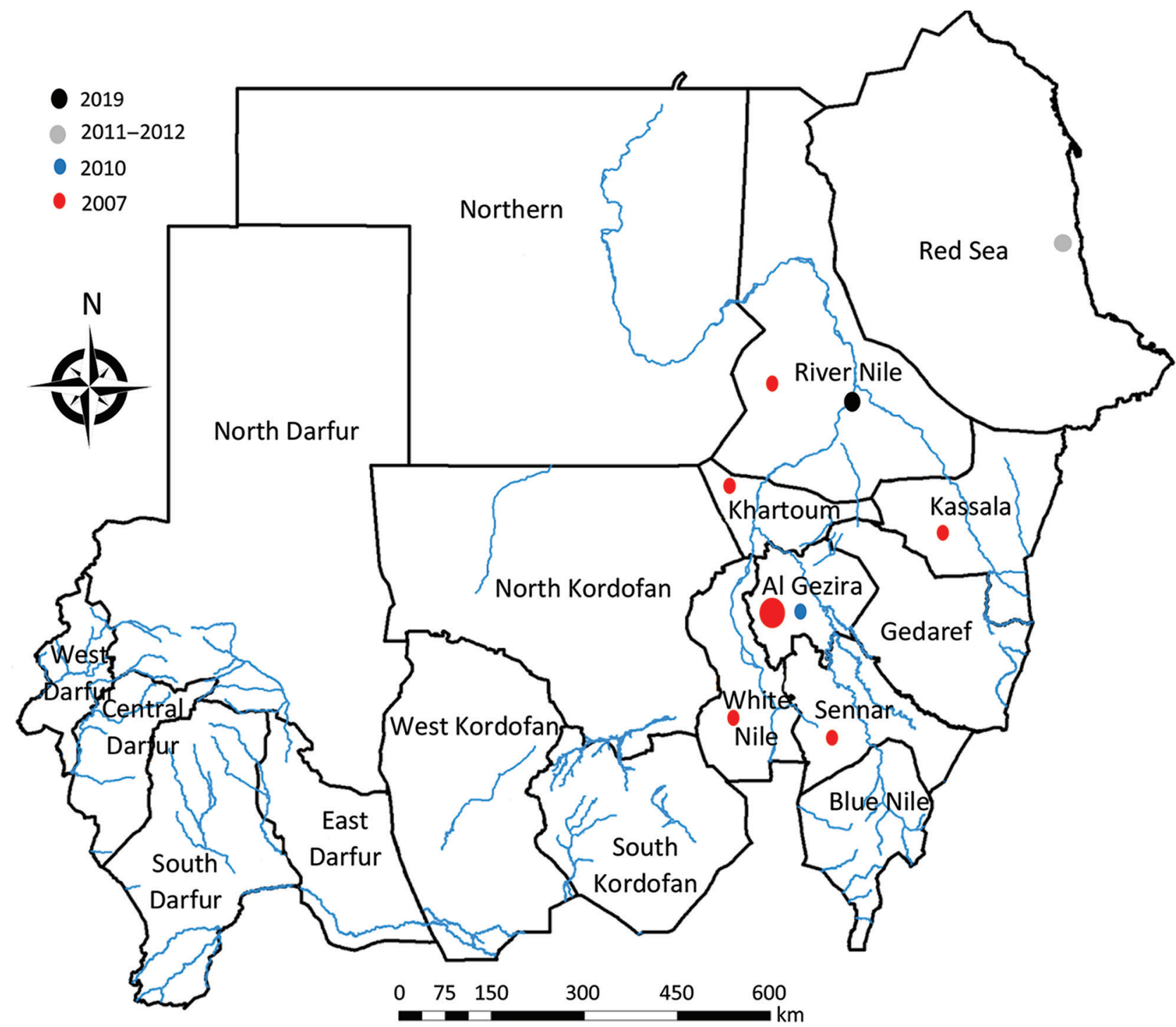

Figure 1. Distribution of Rift Valley fever outbreaks in Sudan, by year.

hemorrhagic manifestations, and headaches; where the patient lived; and if the patient had noted any death or abortion among livestock. We randomly collected 50 blood samples and tested them by reverse transcription PCR using the RealStar Rift Valley Fever Virus RT-PCR Kit 1.0 (Altona Diagnostics GmbH, https:/ / altona-diagnostics.com) in the Sudanese National Public Health Laboratory, Khartoum, Sudan. PCR testing confirmed RVFV infection in 88\% (44/50) of samples.

We report a unique outbreak of RVF that occurred before the typical transmission season, which in Sudan normally corresponds with rain and flooding during September-December. There were also an unusually large number of cases $(1,129)$ and 19 related deaths. Although RVF epidemics and epizo- otics are common in Sudan because of the endemic transmission of RVFV (4), this outbreak was unique in the scale of human and animal infections over only 3 months. The timing of outbreak development was also unusual, which could be attributed to the nationwide political violence that forced many people to move with their animals from RVF-endemic to nonRVF-endemic areas and vice versa (11).

Three major RVF epidemics were documented in Sudan in 2007, 2010, and 2011-2012 (Figure 1) (4). During June 2011-November 2012, a total of 28 RVFV infections were detected among pregnant women in the governmental hospital of Port Sudan in Red Sea state (10). In 2010, the outbreak was more limited in size and geographic distribution; only 18 cases were reported, in El Gezira state (12). In 2007, a total of 747 


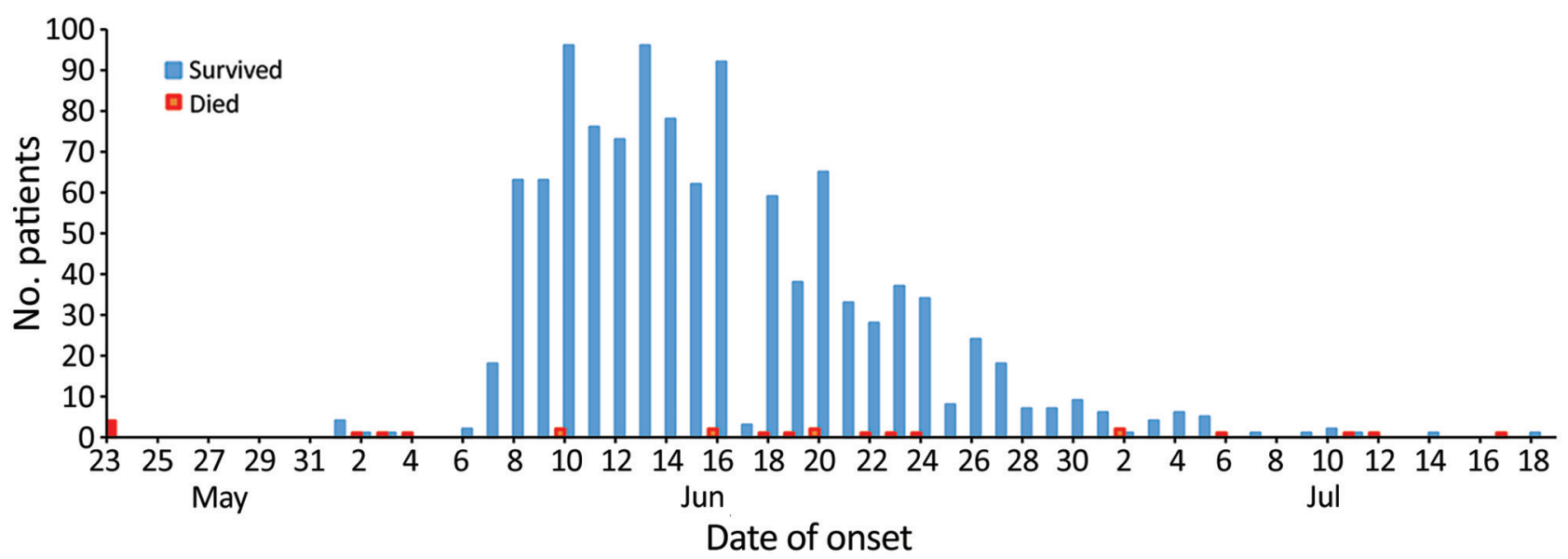

Figure 2. Cases of and deaths from Rift Valley fever, River Nile state, north Sudan, May 23-July 18, 2019.

human RVF cases, including 230 deaths, were reported from El Gezira, Sennar, White Nile, Kassala, Khartoum, and River Nile states; most cases (54\%) and deaths (64\%) were reported from El Gezira state (9).

In Sudan, there is no reliable estimate for RVF death and abortion rates among livestock animals due to limited health surveillance systems for both human and animal populations $(4,9,13)$. However, a 2019 report shared with the World Organization for Animal Health showed that, in sheep, the death rate was $2.4 \%$ and the case-fatality rate $13.5 \%$; in goats, the death rate was $2.1 \%$ and the case-fatality rate $18.8 \%$ (14).

As part of the recent unrest in Sudan, medical and health professionals have been intentionally targeted by military forces for their role in supporting national demonstrations. As a result, both health

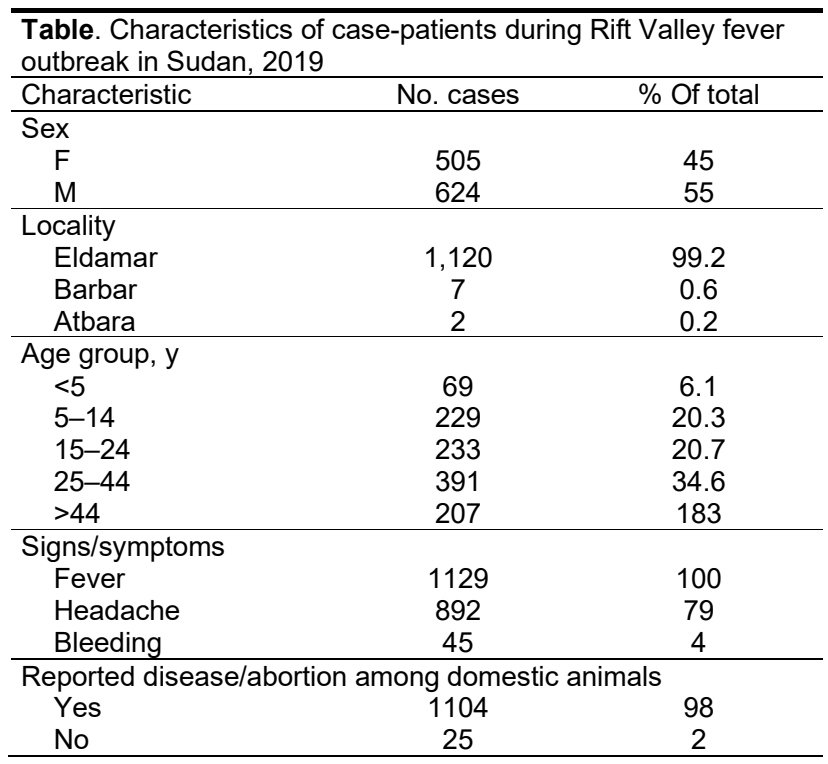

outcomes and records of cases might have been influenced by the escalating political violence throughout the country during the time of the 2019 RVF outbreak (11). These attacks impaired the health system, limiting its capacity to respond to and contain the outbreak in its early stages (11). This health system deficiency is underscored by the limited number of cases reported around June 16, 2019, when the outbreak was at its peak (Figure 1). In addition, Eldamar is a major market for domestic animals, particularly sheep and goats, which could have been an additional risk factor influencing the emergence of RVFV in the area and facilitating spread into other states, particularly Port Sudan in Red Sea state, the main seaport of the country for exporting animals (15). Unfortunately, Sudan typically experiences delays and deficiencies in data sharing during epidemics and health emergencies (13), which likely contributed to the slow reporting of this 2019 RVF outbreak and the general impairment of the health system during a time of national political change (11).

\section{Conclusions}

The risk of exporting RVFV across borders remains poorly characterized but real, stressing the need for a countrywide, One Health survey in Sudan to investigate the prevalence of RVFV among humans and domesticated animals and to identify the risk factors associated with its emergence. Further, we recommend vaccination of domestic animals at risk during the dry season when they cluster together before being moved to open pastures (4) and adherence by health authorities to the core of the World Health Organization's International Health Regulations, including sharing data in a timely manner to promote both local and international safety (13). 
This major RFV outbreak underscores the urgent need in Sudan for improved surveillance systems and a robust health policy for the prevention, early detection, and control of arboviral epidemics. In the case of RVF, early reporting of information regarding animal health is particularly important, because it could be used to contain the disease before it spills over into people.

\section{Acknowledgments}

We acknowledge all the technical support from our colleagues at the state and federal Ministries of Health in acquiring and analyzing data.

S.C.W.'s research is supported by the World Reference Center for Emerging Viruses and Arboviruses, NIH Grant R24 AI120942.

\section{About the Author}

Mr. Ahmed is an arbovirology scientist. His research interests include epidemiology, the dynamics and evolution of arboviral zoonotic diseases, and their control through a One Health strategy. He works toward developing local health policy and global partnerships to prevent and control hemorrhagic fevers epidemics in Sudan.

\section{References}

1. Gaudreault NN, Indran SV, Balaraman V, Wilson WC, Richt JA. Molecular aspects of Rift Valley fever virus and the emergence of reassortants. Virus Genes. 2019;55:1-11. https:/ / doi.org/10.1007/s11262-018-1611-y

2. Weaver SC, Reisen WK. Present and future arboviral threats. Antiviral Res. 2010;85:328-45. https:/ / doi.org/10.1016/ j.antiviral.2009.10.008

3. Grossi-Soyster EN, Lee J, King CH, LaBeaud AD. The influence of raw milk exposures on Rift Valley fever virus transmission. PLoS Negl Trop Dis. 2019;13:e0007258. https://doi.org/10.1371/journal.pntd.0007258

4. Ahmed A, Dietrich I, LaBeaud AD, Lindsay SW, Musa A, Weaver SC. Risks and challenges of arboviral diseases in Sudan: the urgent need for actions. Viruses. 2020;12:81. https://doi.org/10.3390/v12010081
5. Weaver SC, Barrett ADT. Transmission cycles, host range, evolution and emergence of arboviral disease. Nat Rev Microbiol. 2004;2:789-801. https:/ / doi.org/10.1038/ nrmicro1006

6. Elduma AH, LaBeaud AD, Plante JA, Plante KS, Ahmed A. High seroprevalence of dengue virus infection in Sudan: systematic review and meta-analysis. Trop Med Infect Dis. 2020;5:120. https://doi.org/10.3390/tropicalmed5030120

7. Ahmed A, Ali Y, Elmagboul B, Mohamed O, Elduma A, Bashab H, et al. Dengue fever in the Darfur area, western Sudan. Emerg Infect Dis. 2019;25:2126. https://doi.org/10.3201/eid2511.181766

8. Ahmed A, Elduma A, Magboul B, Higazi T, Ali Y. The first outbreak of dengue fever in greater Darfur, western Sudan. Trop Med Infect Dis. 2019;4:43. https:/ / doi.org/10.3390/ tropicalmed 4010043

9. Hassan OA, Ahlm C, Sang R, Evander M. The 2007 Rift Valley fever outbreak in Sudan. PLoS Negl Trop Dis. 2011;5:e1229. https:// doi.org/10.1371/journal.pntd.0001229

10. Baudin M, Jumaa AM, Jomma HJE, Karsany MS, Bucht G, Näslund J, et al. Association of Rift Valley fever virus infection with miscarriage in Sudanese women: a cross-sectional study. Lancet Glob Health. 2016;4:e864-71. https:/ / doi.org/10.1016/S2214-109X(16)30176-0

11. Dahab M, Abdelmagid N, Osama T, Nurelhuda N, Abutalib Z, Spiegel P, et al. Political violence in Sudan: the need for a coordinated, locally led humanitarian health response. Lancet. 2019;394:549-51. https://doi.org/10.1016/ S0140-6736(19)31618-6

12. Aradaib IE, Erickson BR, Elageb RM, Khristova ML, Carroll SA, Elkhidir IM, et al. Rift Valley fever, Sudan, 2007 and 2010. Emerg Infect Dis. 2013;19:246-53. https://doi.org/ 10.3201/eid1902.120834

13. Ahmed A. Urgent call for a global enforcement of the public sharing of health emergencies data: lesson learned from serious arboviral disease epidemics in Sudan. Int Health. 2020 Mar 6 [Epub ahead of print]. https:/ / doi.org/10.1093/ inthealth/ihz122

14. World Organisation for Animal Health. Rift Valley fever, Sudan. Follow-up report no. 1. 2019 [cited $2020 \mathrm{Feb}$ 9]. https://www.oie.int/wahis_2/public/wahid.php/ Reviewreport/Review?reportid=32246

15. Salih HAM, Elfadil AAM. Risk assessment and management for peste des petites ruminants (PPR) in Sudan [PhD thesis]. Khartoum (Sudan): Sudan University of Science and Technology; 2015 [cited 2020 Feb 9]. http:/ / repository. sustech.edu/ / handle/123456789/11968

Address for correspondence: Ayman Ahmed, Institute of Endemic Diseases, University of Khartoum, PO Box 2318, Khartoum 11111, Sudan; email: ayman.ame.ahmed@gmail.com 